\title{
Follow the leader: Child-led inquiries to develop science learning of young children
}

\author{
Pauline Roberts ${ }^{1}$
}

\begin{abstract}
Science education in the early years has been found to be lacking when compared to other content areas, specifically numeracy and literacy. It has been suggested that this lack of opportunity for young children to learn science is due to educator's lack of confidence to teach science, fuelled by concerns regarding a reduced understanding of science concepts. For young children, however, science is everywhere and is embedded in all aspects of their lives as they explore and interact to make sense of the world around them. Given this natural connection to science, it is important for educators to notice and respond to children's interest to encourage science learning to occur. This paper reports on an exploratory research study in which children took the leading role in inquiry-based interactions during off-site school days that took place within a metropolitan city zoo. Through the collection of observations and interactions with the research, several inquiries were documented. The children challenged the educators within the program to follow up on questions posed by them and engage the children across a broad age range in an inquiry to answer these questions.
\end{abstract}

\section{Article History}

Received: 01 August 2021

Accepted: 27 November 2021

\section{Keywords}

Early years science; Childled inquiries; Zoo kinder;

Children's questions

\section{Introduction}

For young children, science is part of their daily lives as they explore their surroundings and try to make sense of their world. It has been suggested that "as soon as children realize they can discover things for themselves, their first encounter with science has occurred" (Tu, 2006, p. 245). Unfortunately, however, educators who work with these young learners often lack both the conceptual and pedagogical knowledge to confidently teach science and as a result implement science learning using formal methods which lead to one-off teacher directed experiences (Gerde et al., 2018) that may be less meaningful to the children. Through an exploratory research approach using an interpretive lens, this study aimed to provide an alternative to these experiences, by allowing children to take the lead on inquiries and therefore, encouraging the educators to develop inquiries that align with these interests. The research took place within an off-site schooling program that engaged children, aged between 3 and 7 years, one day per week in visits to a metropolitan city zoo. It is hoped that these examples from practice will inspire others to firstly notice, and then follow children's questions in a shared learning experience focused on science, but that also incorporates other areas.

Young children are inquisitive and curious, and they learn through exploration with their senses and through asking questions of the adults around them. Research has found, however, that often these questions go unnoticed by educators in the early years which results in missed learning opportunities for both the children and the educators - "...it depends on the teacher's awareness, to bring science to the surface, to make it visible for the children, because if they're not made aware, then it will pass and it doesn't go anywhere" (Campbell et al. , 2015, p. 21).

This lack of noticing can be caused by a number of factors including: lack of time in a busy early years' environment; priority being given to other learning areas, such as numeracy and literacy; or educators lack of science content knowledge to firstly identify the science opportunity, then confidently 
follow this science learning opportunity through. In a widely cited study in 2006, Tu identified that while $50 \%$ of the classrooms he visited contained a science area, $86.8 \%$ of the activities completed within the classrooms were not science related. There were no instances of incidental teaching of science and even when plants were present in $70 \%$ of classrooms, these were not there for science-related purposes. This led to the conclusion that "preschool teachers did not provide adequate science activities and preschool teachers also missed teachable moments" (Tu, 2006, p. 251). Similar research by Saçkes et al. (2011) also identified that science learning was not typical in early childhood classrooms. Both Tu (2006) and more recent research by Edwards and Loveridge (2011) called for "teachers to rethink the purposes and practices of science teaching, inferring the importance of reflective practices" (p. 30) in examining why science may be missing.

It has been identified that early childhood teachers lack confidence in teaching science to young children (Edwards \& Loveridge, 2011) or lack self-efficacy in science teaching (Oppermann et al., 2019). Studies identify that teachers in early childhood settings may not be predisposed to teach science (Reinoso et al., 2019), may not have had exposure to enough science-based courses in their training (Saçkes, 2014), or lack of confidence in planning and demonstrating some science topics, which reduces focus in these areas (Oon et al., 2019). It is this lack of confidence that inhibits the noticing of science learning opportunities within early years classrooms and is why this research focused on following children's questions as the starting point for inquiries rather than relying solely on educators to plan the tasks.

Research has similarly identified that early years' teachers lack the appropriate level of content knowledge to teach science concepts and skills (Barenthien et al., 2018; Brenneman, 2011; Nilsson \& Elm, 2017). Science concepts may be seen as difficult to understand (Abdo \& Vidal, 2020), as may be the underlying constructs related to the Nature of Science (NoS) itself as a starting point for teaching young children (Akerson, 2019). While the science concepts in the early years often relate to the biological sciences as children explore their natural world (Larimore, 2020), subject areas such as chemical or physical sciences may be seen as more difficult to understand and teach (Abdo \& Vidal, 2020) despite being significant in young children's sciencing of the material world (Areljung, 2019). There may also be confusion that young learners cannot understand concepts when, in fact they can, but they are unable to articulate this understanding. (Saçkes, 2015). Teachers who feel inadequate in their science knowledge may lack efficacy (Oon et al., 2019) to adapt content to the early years (Akerson, 2019) which is another reason to rely on the children's questions in setting the inquiry focus as they guide what they are interested in and the types of content that could be explored. The teachers can then complete research within the areas identified by the children to ensure they are learning concepts they can engage the children with at the appropriate level.

In addition to knowledge of content, knowledge is shown to be lacking in the pedagogical strategies used to teach science (Abdo \& Vidal, 2020; Afifah et al., 2019; Areljung, 2019). Lee Shulman (1986) is recognised as being one of the first to identify that effective teaching requires not only content knowledge (CK) but pedagogical knowledge (PK) which is significant in planning for science if either of these are lacking. Researchers since Shulman have used the concepts of content and pedagogical knowledges to examine educator's abilities within these domains (Nilsson \& Elm, 2017). Teachers have been found to lack these two distinct types of knowledge and while some studies have focused on improving knowledge, there may still be a lack of confidence in utilising the full range of science teaching methods in early years' environments. These findings further support the following of children's leads in teaching science as the children can help to determine not only what they want to learn (the content) but also be engaged in deciding how they want to learn it (the pedagogical strategies). The children can ask to read books, to search the Internet, to ask an expert or to try an experiment as part of their inquiry. The educator can follow this idea through, to provide the required resources for these explorations to happen and be adding strategies to their repertoire along the way.

Based on these identified concerns for educators in teaching science, and the natural connection young children have to learning science, this exploratory study set out to identify:

- If child-led inquiry focused on children's interest led to the learning of science concepts; and 
- What role the educators had in these inquiries as a model for improving science teaching in the early years.

To explore these questions, the researcher worked with one community-based school setting where the children attend off-site schooling one day each week.

\section{Method}

The research reported here, utilised an exploratory research approach where the focus was on collecting large amounts of unstructured information to then interpret and discuss (Check \& Schutt, 2012). The exploratory approach was chosen as the researcher had an idea of what would happen during the research (based on experience of off-site school) but had "no clear expectation of what to expect" (Cohen \& Manion, 1994, p. 259). The goal was not to prove or disprove a hypothesis but to identify the roles played by the children and the educators in the process of learning science concepts (Cohen \& Manion, 1994). Through an interpretive lens, aligned with participatory research methods (Denzin \& Lincoln, 2011), the research explored the interactions of children aged between 3 and 7 years, and their educators in an offsite schooling program to examine the social constructions of science learning that were being established (Check \& Schutt, 2012). As the researcher was known to the educators and the children, they were able to engage in participatory observations of the normal activities that the children and educators undertook during their visits to the metropolitan zoo as part of their regular off-site schooling program. The data were collected through a range of observation methods and the inquiry projects were reviewed for the interaction patterns that developed from the children's questions, answers, and explorations.

\section{Participants}

The school that hosted this research is a community school that has a focus on Science, Technology, Engineering, The Arts and Mathematics (STEAM) learning and inquiry. The school caters for children from pre-kindy ( 3 years old) through to Year 1 (6 years old) and incorporates an off-site schooling day each week with the setting changing each school term. Previous off-site days have been spent in local parks, alongside the river and a science centre. On the off-site day, the parents either deliver and collect the children from the external site or the group meets at the school and utilises spaces within walking distance of the school or catches public transport to visit specific sites. This study engaged with the children as they spent a term visiting the metropolitan city zoo that was close to the school and facilitated parents dropping off and picking up from the zoo site.

The off-site group consisted of 12 children each day -7 in Kindy (4-5 years old); 3 in Pre-Primary (56 years old); and 2 in Year 1 (6-7 years old); with 2 teaching staff each day although four different educators across the term. The educators held early childhood teaching qualifications so were generalist teachers although the focus of the setting meant they had completed professional learning on a range of science concepts and the inquiry process. Three different parents also joined the group on separate observation days. These parents were professionals in their fields although none with a specific science focus - one was in marketing, one in law and the other ran his own business. The sample was selected based on school enrolment patterns, staff rosters and parent availability to attend on that particular off-site school day.

Informed consent for engagement in the research was provided by the principal, the educators and the parents of the children enrolled on that day within the school through a signed consent form at the beginning of the research project. Assent was also given by the children within each interaction before notes were made or photographs were taken to ensure they were willing to be involved in the data collection for the project. This was a verbal agreement between the children and the researcher at the time of the observation or conversation taking place.

\section{Data Collection}

The data collection for this project utilised a mixed methods approach based on participatory methods of observation and discussion through interactions with the children and adults as they explored their zoo inquiries. The documentation of these observations and interactions took multiple forms within 
the research process, including field notes, reflections, photographs, and educational documentation.

- Field notes were taken of the questions the children asked and the responses given by the educator and researcher during the time spent exploring the zoo. All children engaged at least once across the observation period with these data collection processes.

- Photographs were taken of the children interacting in inquiries as well as of the Floorbook $\odot$ pages that documented these inquiries during and after their implementation.

- Reflective notes were made of discussions with educators throughout the observation times and between visits when they wanted to discuss possible avenues for future inquiries based on the previous visits. The teaching staff varied in knowledge, skills, experience, and confidence in teaching science to this age group of children and as such, a culture of mentoring and ongoing learning was present within the staff team

- Additional reflective notes were taken of discussions with some parents who attended zoo kindy as a volunteer helper on some of the observed days. These often included questions about the philosophy of the inquiry-based program and why it was valued by the school.

\section{Data Analysis}

There were substantial amounts of qualitative data collected and documented through the observations and interactions completed on the zoo visits. Analysis of the data began with the identification of factors based on "a hunch to the factors that might emerge" (Child, 1970, cited in Cohen \& Manion, 1994, p. 331) to examine the structures and relationships connected to the human experience (Cohen \& Manion, 1994). These initial factors were initially identified as (1) questions, (2) interactions, and (3) resources. Using these. factors, the data were sub-divided for descriptive analysis (Denzin \&Lincoln, 2011). As the focus was on interpreting the specifics (Cohen \& Manion, 1994) and relationship of these factors, the decision was made to review and present the findings in relation to the individual inquiries and how these factors were present in each.

\section{Results}

Across the term of observations with the children as they attended zoo kindy, multiple inquiries were undertaken based on questions from the children and interactions with the educators. For the descriptive discussion as results of this study, each inquiry is considered as a unique case and the data were reviewed with the factors of questions, interactions, and resources towards the research questions. A total of four explicit inquiries are reported on in this paper from across the term with some lasting for one visit, while others built upon learning from a previous visit to inform a future interaction - sometimes across several weeks. Several additional inquiries were also completed across the term of visits to the zoo and while these were valuable, they are mentioned as one block rather than detailed as a unique inquiry due to less plentiful data or less children being engaged.

\section{Inquiry 1: “The Rickety Bridge”}

Each week at zoo kinder incorporated a 'human vote' where the children would vote by physically posing as the attraction they most wanted to see first. The results of this vote then determined the journey to be taken as the group moved around the zoo on that particular visit. Across the first weeks of zoo kinder, the older children convinced the younger children that based on their prior experience, (they had experienced zoo kinder the year before) the Rickety Bridge was the best place to visit and should be completed first.

The Rickety Bridge was erected across a waterway that flowed down through a bushy section of the zoo, and as the name suggests, it was a bridge that moved as you went across it. The questions associated with this zoo attraction related to the materials used in constructing the bridge - rope, nets, wood, steel string; and how these materials led to the rickety nature of the crossing - it was hung from trees and posts rather than being fixed to the ground across the middle because there was no ground - just water.

Some of the younger children were very unsure of using this bridge to get across and this led to 
Follow the leader: Child-led inquiries to develop science...

interactions and investigations related to the 'secret path' that went behind some bushes and around a different way to avoid crossing the rickety bridge. The children discussed why the secret path was there for safer trail through the bush, to avoid the bumpy bridge, for prams and trolleys to use, and to show different plants.

On one visit after the rickety bridge had already been explored as the first stop, the group came across some workers constructing a new wooden bridge to get to the elephant viewing platform. The children again engaged in further discussions, this time comparing the materials being used for this bridge - different types of wood; and how this construction differed from the rickety bridge - it was fixed to beams that ran along the floor. This bridge was described as heavier because it was made of wood. This fixed design was considered much more appropriate for this bridge that had many more visitors accessing this area than the rickety bridge's bush and there was no water to get over that needed the bridge to be suspended.

\section{Connection to Research Questions}

This inquiry demonstrated the link to the children's interest that led to science learning that was facilitated and supported by the educators. The learning for the children in this inquiry related to the properties of materials in terms of what to use in what situations as well as the engineering required for bridge design and the bridges being fit for purpose. Comparison of plant life was also completed as the group of younger or less confident children avoided the rickety bridge and there was discussion of surfaces best suited for different types of zoo visitors and what this diverse group needed. The interactions with the educators extended the children's thinking beyond the simple materials used to create the bridge to the engineering concepts that required the bridge to be constructed as it was. Questions were posed, particularly when compared to the 'other' bridge about why these materials? Why this design? The group that was less confident on the bridge were less engaged with this inquiry, but the older children did connect this to other experiences and led into the future inquiries back in the classroom in physics. No additional resources were required in this inquiry although the design of the bridge was documented in the Talking and Thinking Floorbook (

\section{Inquiry 2: "The Reptile House"}

On a different day at the zoo, the children voted to visit the reptile house. Within this area, there is a glass fenced enclosure in the centre of the room that houses numerous Australian lizards that can be seen by the children at floor level. There are large heat lamps hanging from the ceiling and the lizards often congregate under these. From previous visits to this area, the 6-year-olds were able to tell the younger children that the lizards were in these spots because it was just like lying in the sun which the lizards did to "warm their body temperature". As these lizards moved around, there were a range of tracks being made on the sand floor and a group boys began trying to follow the tracks to identify which lizard had made each unique track and how these were made. Feet and tails were identified as the tools used in track making and so the width of tail and size of feet made a difference. "Mr Lizard is making a trail (squiggly lines) with his tail" was the conclusion.

Also, within the reptile house, there was one snake in a glass case fixed into the wall that was long and sleek except for a large bulge in one section at about the middle of the snake. The provocation was "I wonder why there is a big bulge" to which a 3-year-old responded that "the tummy has gotten bigger because the snake had eaten too much dinner". This led to discussion of what the snake could have eaten, and the group used the information chart on the wall that detailed diets of reptiles. From this, it was decided that it was probably a bird, but a small one like a willy wagtail not a big one like a magpie.

In another glass enclosure within the reptile house, there was a snake who was in the process of shedding its skin. One 4-year-old was particularly interested in this and concerned that this shedding process was painful to the snake. He had enough confidence to approach a zoo volunteer to ask if this process was painful to the snake and was relieved when the zoo helper reported that it was not. The discussion further ensued about what snakes ate and after initially guessing leaves, the discussion moved 
to name mammals as the snake's main food source and further conversation about what a mammal was and how it was different to a reptile who laid eggs and were cold blooded. The 4-year-old then asked how the reptile kept warm, and the volunteer pointed out that in their natural world they lived underground then came out to the sun to warm up, but in the zoo, they had the heat lamp which the volunteer then pointed out to the inquisitive child. The discussion between this child and the volunteer rounded out with confirmation that the snake used the heat to warm up enough so they had energy to hunt. This discussion made an impression on this young learner as the child was able to recall much of this learned information in the following week when he returned to the reptile house.

\section{Connection to Research Questions}

Biological sciences were the focus of these interactions and through follow-up questions deeper learning occurred. By revisiting the reptile house again in future visits, it became clear that the inquiry was led by the students and the learning that happened within these interactions was being retained by the young children as they could recall the content learned through the previous interactions. This allowed them to extend their own inquiry each time they returned to this environment. The reptile house provided several small child-led inquiry cycles to be implemented where the children identified the question and then identified resources available to find out the answers to these questions. While on some occasions the educator interacted to provide prompting questions, at other times the children utilised other resources such as the information charts on the walls within the reptile house or the zoo volunteer to answer their inquiry questions. The confidence to not rely on peers or teachers allowed for more detailed discussions of what the children were interested in by accessing 'experts' that were available.

\section{Inquiry 3: "Waterproof or not"}

A favourite part of each zoo visit was not related to the animals. The playground area adjacent to where the children had lunch incorporated a man-made stream where the water was pumped from a large ceramic bowl that filled and then created a waterfall at the top of the hill. The water then flowed through a curving channel to the 'pond' at the bottom where the water flowed into a grated drain and was recycled back to the top. The children loved getting completely drenched within this area before getting changed to do one more animal visit or complete the Floorbook@ documentation before going home. The play within this stream area opened possibilities for several inquiries connected to water and water use but the fact that the children's clothes kept getting wet, led the children to ask questions about clothing selections and discussions that they should wear clothes that were waterproof - but what did this mean?

The resulting waterproof inquiry ran over several weeks and incorporated numerous individual explorations. On one visit, based on the children's lack of understanding of what materials were waterproof, the educator provided a bag of fabric scraps to the children who subsequently explored which pieces were waterproof or not. Initially, there was a great deal of misconception about what waterproof meant, especially among the 4-year-olds. Several the children submerged the material into the water and claimed, "its waterproof" and when asked why, they detailed "because it got wet". The distinction some children made here was they described it as getting wet but not soggy as soggy things were not waterproof. One of the 5-year-olds came in at one point during the exploration and said that waterproof meant it helped people not to get wet - like a raincoat, while a 6-year-old added that waterproof things can go in the water and not get wet. This provided the language for the children to use in their inquiry practices. After further exploration, the 4-year-old then explained that some materials were not waterproof because they got wet in the man-made stream. This exploration clearly identified the developmental continuum at play within these open-ended inquiries and allowed the younger children to learn from older peers who were able to articulate what waterproof meant and this altered the younger children's understanding of the concept. This learning was led by the children and although the educator provided the materials (resources), it was the interactions among the children themselves that facilitated the learning.

To further develop the concept of waterproof in a future week, the educator took a large roll of paper, a roll of clingwrap and a roll of aluminium foil to the zoo. During the visit, the children engaged with making boots out of the different materials to see which ones were best in keeping their feet dry. This 
exploration extended upon the concept of waterproof but also related the learning to children's own experiences in terms of wearing boots and demonstrating the connection between learning and the children's everyday lives - an important process in helping children to see the purpose in their learning. The teacher-directed interaction utilised additional resources based on the children's questions. While there were issues with the design and construction of the boots - mostly related to the nature of the materials and difficulties with construction, the children were able to determine that the paper was the least effective material for boots, and the plastic wrap the most successful material to use when making boots to keep feet dry. The children also identified from this that this was why gum boots from the shops were made of plastic although they did acknowledge the plastic of gumboots was thicker than the cling wrap to effectively keep feet dry in the rain.

At the top end of the stream, the children were also experimenting with stopping the flow of water from the waterfall/fountain at the top. On one visit, a 4-year-old boy spent most of the time allocated for the playground sitting in the bowl the water would flow from so that his bottom and legs blocked the stream of the water. This action meant the bowl collecting the water for the waterfall would fill to overflowing. He would use his arms to push his body up which would allow the water to flow in a rush "through a tunnel" and then he would drop down and block it off again. In discussion and through experimentation, he tried other body parts to block the flow of the water- his hands, his feet, his arms, but he identified that the bottom was the most effective as it slowed the flow of water to almost nothing. This led to a game where he would sit and wait until the bowl was full and then release the water in a rush and see how that impacted on his friends playing in the water further down the stream.

\section{Connection to Research Questions}

In this inquiry, there were several points where the educator had a direct role in facilitating the inquiry. Following from the children's interest in the water, and the problem of wet clothing, they provided additional resources and planned specific interactions to extend the children's thinking on the concept of waterproof. The different levels of understanding among the children meant that the inquiry had a broad scope but the interactions among the older and younger children allowed the shared learning to occur. The interaction with water allowed for chemical science explorations in terms of the properties of materials as well as technology related to choosing materials fit for purpose. The misconceptions about waterproof were corrected through interactions among the multi-aged group with older children supporting the learning of the younger ones. Water allows for a great deal of topics to be examined and many open-ended explorations to take place.

\section{Inquiry 4: “What do they wear?"}

The final distinct inquiry being detailed in this paper was the work the children did in relation to the coverings on the animals they visited. Across several weeks of visiting the zoo, the children discussed whether animals were covered in fur, feathers, skin, or scales and why there were differences. The children identified that scales allowed heat to be absorbed through the skin, fur kept animals warm, the shells of the tortoises kept them safe, and the feathers on the birds were a light covering so that the birds could fly. The children documented the animals by body covering in the Floorbook $@$ and regularly enjoyed a game of musical stop just inside the zoo entrance where a play area incorporated large concrete pipes painted to represent different coverings of several animals, for example a zebra, a cheetah, a snake. Through the game, the children had to identify what the covering was that they had selected to sit on when the music stopped, which animals had this covering, and sometimes why this was the best covering for that animal. An extension of this initial inquiry with some of the older children was to discuss the colours of the coverings too and identify why different animals had specific colours and patterns. This was highlighted when the group identified that many African animals - the painted dogs, the tiger, the giraffe, had patterned fur to hide in the grasses and jungle areas.

\section{Connection to Research Questions}

The musical stop game allowed the educators to reinforce, in a fun way, the work completed in the 
Floorbook $@$ on animal coverings and the reasons behind the type, colour, and patterns of these. The children's inquiry started with questions about why animals had different coverings and the specific focus was determined by their preference for particular animals but also their understanding of climate, habitats and species of animals, depending on their age and interest. The use of the provided resource allowed connections to be made by the children with minimal additional resources being developed by the educators. These resources instead provided for alternate interaction patterns.

Different environments were identified as a key determinant of the type of covering animals had both in terms of type and colour. The biological concepts were learnt as the children explored why different coverings were more suitable in hot or cold climates as well as how coverings protected animals in terms of camouflage or physical environments. This learning occurred across multiple zoo visits and was reinforced through many other inquiries - the reptile house, the water play, and the elephant encounter.

\section{Other Inquiries}

While these four case examples are more detailed interactions of the learning that occurred under the children's direction, there were other inquiries across the term of zoo kindy. These included discussion of why emus had long strong legs and what the role of the short wings were - to turn when running fast; how the tortoise was eating the leaves, especially when the zoo keeper was using what looked like a toothbrush to sharpen the animal's beak; what nocturnal means and how the building in the zoo enabled the animals to be seen during the day; why the baboons have red bottoms which is of course hilarious as any talk of bottoms is; how to keep the zoo area clean, including litter, plant materials and most importantly what does the zoo do with all the poo? In case you wanted to know the answer to that last question, they share it with local councils and other organisations to be used as compost in gardens.

What was identified through these inquiries was the role of the questions, both from the children and the educators, to connect children's learning with other inquiries and other ideas. Sometimes educator interactions provided direction to the children to extend thinking or offering additional resources to answer increasingly complex questions. Very little was added to the environment by the educators and the process of following children's questions proved to engage all children in learning across the term of visits.

\section{Discussion}

The inquiries detailed in the results section demonstrate the ability of young children to learn a range of science (and other subject area) content through their own inquiries. The educators interacted throughout these to assist in answering questions and seeking out resources to support the children's developing understanding. Much of this was done based on the children's own interests and questions so they had control over what they were learning and investigating. Throughout this process, the educators were able to follow the children's lead, which reduced the pressure on the educators to identify areas for inquiry or to plan expansive activities that may have not related to the children in terms of age, interest, or current knowledge. The closing section of this paper focuses back to the research questions to provide support for the pedagogy of following the children's lead as well as encourage educators to embrace early childhood science from this child-initiated inquiry perspective.

\section{Can Children Learn from Child-Led Inquiries?}

The examples presented as cases within the results section demonstrate that child-led inquiries can provide a multitude of learning opportunities for young children. The inquiries developed from experiences the children were engaged in through hands-on processes where they could ask questions and work towards identifying answers,

The multi-age context allowed additional interaction and scaffolding of learning where younger children learned from their older, more knowledgeable peers and through this, misconceptions were clarified. The inquiries being undertaken were largely owned by the children which resulted in them being at an appropriate level of difficulty and focused on topics of interest. As some of the older children had experienced the zoo setting in previous years, they had already mastered these concepts and moved to 
more complex ones. The open-ended nature of the inquiries meant that the children could step in and out of inquiries at their current level and then be extended incrementally by more learned peers - it was Vygotsgy's Zone of Proximal Development (cited in Tudge, 1992) in action.

When the children were responsible for developing the questions and the focus was on their inquiries, they determined how to best adapt concepts to their developmental level (Akerson, 2019). While much of the content covered across the term related directly to the biological sciences and the natural world (Larimore, 2020), there was some exploration in other science areas as well as other subject domains. The inquiries were meaningful to the children and authentic as they controlled both the content and the process which is empowering to them and allows them agency over their learning (Duncan, 2018). The retell of experiences on subsequent visits and documentation of the inquiries demonstrated the learning that was taking place for each child as they engaged with these inquiries.

\section{What Role Does the Educator Take in Child-Led Inquiries?}

The main role of the educator throughout these inquiries was to ask prompting questions and to scaffold the inquiries identified by the children. The multi-aged groups and the peer social learning that was happening allowed the educators to deepen their understanding of the different stages of the learning of certain concepts through interactions with individuals and small groups to effectively facilitate and scaffold the children's learning across these stages.

The process of following children's questions was also beneficial to the educators, particularly those with less experience with inquiry because interactions enabled them to relax and let the children problem solve for themselves. An example of this was the waterproof inquiry with one of the newer staff members. She had decided to bring the fabric scraps to the zoo for the children to engage with the experiment about what was waterproof, but during the exploration was unsure when to step in and if they should be providing the correct answers to the children or not. Through providing the children with the resources and the time, the educator was able to observe the children's problem solving and eventually the older children supported the learning of the younger ones. This alleviated the concerns on how to effectively describe what waterproof meant at a level the children could understand and allowed the educator to engage without having to be the expert in the situation. The interaction improved her confidence and selfefficacy (Oon, et al., 2019) around this concept and led to her next scaffolded experiment with the paper, foil, and cling wrap to create boots to keep feet dry.

By having the children take the lead, the educators were able to complete additional research and scaffold explorations to meet the needs of the children, but the process also assisted in identifying what content knowledge was required (Abdo \& Vidal, 2020). In addition to this, the focus on the children's questions including allowing them to decide how to answer the questions, decreased the reliance on the educators pedagogical knowledge (Afifah et al., 2019). This allowed the educators to be co-learners in the process (Henningson, 2013) and engage with the inquiry with more confidence, rather than being the director of the learning and working with limited strategies.

An additional role of the educator was in relation to the provision of resources. While the. zoo environment itself provided many of the resources for these inquiries with little additional required. The more teacher-led inquiries such as those related to waterproof materials saw that the educator scaffold the experiment with the provision of firstly a bag of materials and secondly the paper, foil, and cling wrap to create boots to keep feet dry were really the only additional resources added too inquiries. The child-led inquiries mostly used what was already there including displays, such as the reptile house inquiry, where the children utilised the information posters available as well as the zoo helper's expertise to answer their questions and were satisfied with that.

The documentation was the other area where the educators added materials and other supports to the reporting elements of the inquiries, but again the children completed this in their own ways and often took over the process. Their voices came through in the reporting of inquiries and this is an important part of the inquiry process (Duncan, 2018). 


\section{Pauline ROBERTS}

\section{Conclusion}

The examples provided throughout this research have highlighted how much children can learn when they are given agency over their learning and are provided with the resources to make connections and apply their newly acquired knowledge into alternate contexts across numerous weeks of visiting the same setting. The depth of inquiries and the development of the educators' science educational abilities throughout this process was also an outcome of the engagement with the zoo inquiries and provides support for the approach to be more widely implemented.

The findings of the study support the implementation of child-led inquiries through multiple interactions within diverse contexts and demonstrate that repeated visits to the same location are important not only for children but the educators as well. By having the opportunity to revisit the site, the children could explore more deeply on each visit and reinforce their learning. The educator was also able to prepare based on previous interactions for additional facilitated discussions and resources.

Additionally, the findings support the interaction of children across multiple year levels where older or more experienced peers can support the learning of others and assisted the educators in mapping learning and will enable them to provide further scaffolding in future inquiries. Research into this model and these processes will continue and is planned to involve additional educators and learning sites to further support the use of this process both within this school context, but also outside of it. Further research will provide additional examples for other educators within the field of early childhood and primary school science in relation to how child-led inquiries can effectively support not only young children's science learning but the development of educators' content and pedagogical knowledge and confidence to effectively teach science in the early years.

\section{Declarations}

Acknowledgements: The researcher would like to acknowledge Christy-Lee, Rachel, Remi, Kate and of course, Tanya - the teachers of the Kindy as well as the children of the school for allowing me to join in their inquiries at the zoo to learn along with them about their inquiry topics and the processes of undertaking them.

Authors' contributions: Not applicable - single author.

Competing interests: Not applicable.

Funding: Not applicable - unfunded project.

\section{References}

Abdo, K., \& Vidal, C. C. (2020). Learning about science in preschool: Play-based activities to support children's understanding of chemistry concepts. International Journal of Early Childhood, 52(1), 17-35. https://doi.org/10.1007/s13158-020-00259-3

Afifah, R. N., Syaodih, E., Setiasih, O., Suhandi, A., Maftuh, B., Hermita, N., Samsudin, A., \& Handayani, H. (2019). An early childhood teachers teaching ability in project based science learning: A case on visible light. Journal of Physics: Conference Series, 1157(2), 022049. https://doi.org/10.1088/1742-6596/1157/2/022049

Akerson, V. L. (2019). Teaching and learning science in early childhood care and education. In C. P. Brown, M. B. McMullen and N. File (Eds.), The Wiley handbook of early childhood care and education (pp. 355-375). John Wiley \& Sons. https://doi.org/10.1002/9781119148104.ch16

Areljung, S. (2019). How does matter matter in preschool science?. In C. Milne and K. Scantlebury (Eds.), Material practice and materiality: Too long ignored in science education (pp. 101-114). Springer. https://doi.org/10.1007/978-3-030-01974-7 8

Barenthien, J., Lindner, M. A., Ziegler, T., \& Steffensky, M. (2020). Exploring preschool teachers' science-specific knowledge. Early Years, 40(3), 335-350. https://doi.org/10.1080/09575146.2018.1443321

Brenneman, K. (2011). Assessment for preschool science learning and learning environments. Early Childhood Research \& Practice, 13(1), $1-9$.

Campbell, C., Jobling, W., \& Howitt, C. (2015). Science in early childhood. Cambridge University Press. https://doi.org/10.1017/CBO9781139923804

Check. J. \& Schutt, R. K. (2012). Research methods in education. Sage. https://doi.org/10.4135/9781544307725

Cohen, L. \& Manion, L. (1994). Research methods in education (4 ${ }^{\text {th }}$ ed). Routledge. 
Follow the leader: Child-led inquiries to develop science...

Denzin, N.K. \& Lincoln, Y.S. (Eds.). (2011). The SAGE handbook of qualitative research (4 $\left.4^{\text {th }} \mathrm{ed}\right)$. SAGE

Duncan, R. (Ed.). (2018). Journeys of inquiry. Association of Independent Schools of Western Australia.

Edwards, K., \& Loveridge, J. (2011). The inside story: Looking into early childhood teachers' support of children's scientific learning. Australasian Journal of Early Childhood, 36(2), 28-35. https://doi.org/10.1177/183693911103600205

Gerde, H. K., Pierce, S. J., Lee, K., \& Van Egeren, L. A. (2018). Early childhood educators' self-efficacy in science, math, and literacy instruction and science practice in the classroom. Early Education and Development, 29(1), 70-90. https://doi.org/10.1080/10409289.2017.1360127

Henningson, M. (2013). Making sense of experience in preschool: Children's encounters with numeracy and literacy through inquiry. South African Journal of Childhood Education, 3(2), 41-55. https://doi.org/10.4102/sajce.v3i2.39

Larimore, R. A. (2020). Preschool Science Education: A Vision for the Future. Early Childhood Education Journal, 48(6), 703-714. https://doi.org/10.1007/s10643-020-01033-9

Nilsson, P., \& Elm, A. (2017). Capturing and developing early childhood teachers' science pedagogical content knowledge through CoRes. Journal of Science Teacher Education, 28(5), 406-424. https://doi.org/10.1080/1046560X.2017.1347980

Oon, P.-T., Hu, B. Y., \& Wei, B. (2019). Early childhood educators' attitudes toward science teaching in Chinese schools. Australasian Journal of Early Childhood, 44(4), 423-435. https://doi.org/10.1177/1836939119870890

Oppermann, E., Brunner, M., \& Anders, Y. (2019). The interplay between preschool teachers' science self-efficacy beliefs, their teaching practices, and girls' and boys' early science motivation. Learning and Individual Differences, 70, 86-99. https://doi.org/10.1016/j.lindif.2019.01.006

Reinoso, R., Delgado-Iglesias, J., \& Fernández, I. (2019). Pre-service teachers' views on science teaching in Early Childhood Education in Spain. European Early Childhood Education Research Journal, 27(6), 801-820. https://doi.org/10.1080/1350293X.2019.1678720

Saçkes, M. (2014). How often do early childhood teachers teach science concepts? Determinants of the frequency of science teaching in kindergarten. European early childhood education research journal, 22(2), 169-184. https://doi.org/10.1080/1350293X.2012.704305

Saçkes, M. (2015). Kindergartners' mental models of the day and night cycle: Implications for instructional practices in early childhood classrooms. Kuram ve Uygulamada Ĕ̆itim Bilimleri Dergisi, 15(4), 997-1006.

Saçkes, M., Trundle, K. C., Bell, R. L., \& O'Connell, A. A. (2011). The influence of early science experience in kindergarten on children's immediate and later science achievement: Evidence from the early childhood longitudinal study. Journal of Research in Science Teaching, 48(2), 217-235. https://doi.org/10.1002/tea.20395

Shulman, L. S. (1986). Those who understand: Knowledge growth in teaching. Educational researcher, 15(2), 4-14. https://doi.org/10.3102/0013189X015002004

Tu, T. (2006). Preschool science environment: What is available in a preschool classroom? Early Childhood Education Journal, 33(4), 245251. https://doi.org/10.1007/s10643-005-0049-8

Tudge, J. (1992). Vygotsky, the zone of proximal development, and peer collaboration: Implications for classroom practice. In L. C. Moll (Ed.), Vygotsky and education: Instructional implications and applications of sociohistorical psychology (pp. 155-172). Cambridge University Press. https://doi.org/10.1017/CBO9781139173674.008 